\title{
The Vector Control Signal Processing Blockset for Use with Matlab and Simulink
}

\author{
Rui Esteves Araújo \\ Faculty of Engineering of the \\ Universidade do Porto \\ Rua dos Bragas, 4099 Porto Codex, \\ Portugal
}

\author{
Américo Vicente Leite \\ Institute Polytechnic of Bragança \\ Quinta de Sta. Apolónia, \\ Apartado 134, 5300 Bragança, \\ Portugal
}

\author{
Diamantino Silva Freitas \\ Faculty of Engineering of the \\ Universidade do Porto \\ Rua dos Bragas, 4099 Porto Codex, \\ Portugal
}

\begin{abstract}
This paper describes the newly developed Vector Control Signal Processing (VCSP) blockset for use with Matlab ${ }^{(B)}$ and Simulink ${ }^{B}$. The originality of this blockset consists on the extension of Simulink for design, simulation and prototyping of signal processing algorithms in motion control systems. This blockset is the first know collection of Simulink blocks to bridge the gap between digital algorithm development and subsequent implementation in motion control systems. The VCSP blockset together with Real-Time Workshop uses the inkerent visual programming techniques of Simulink and a number of pre-built blocks to reach the above goals. Due to its open and flexible nature this approach is also very useful as a tool for teaching. This paper is focused on modelling and simulation of motion control systems, in particular employing rotating $\mathrm{AC}$ machines and vector control methods. The basic of blockset functions and some examples of modelling techniques for simple drive and complex drive structures are presented. Simulations results are also presented and discussed.
\end{abstract}

\section{NTRODUCTION AND MOTIVATION}

The connection between modern simulation tools and the development of visual design concepts is continually shortened by the progress of computing power. Faster and faster processors allow to treat more and more sophisticated simulations tools. Visual design is a methodology for developing digital algorithms graphically, by simply connecting functional block icons together. Today, numerical simulation is an essential tool for the conception, design and test of signal processing algorithms. In particular, it is very useful for choosing and adapting the control structure and algorithms for machineconverter associations.

Various software packages for simulation of electronic circuits, like SPICE [1] and SABER [2], power networks EMTP [3], EUROSTAG [4], or specialised simulations tools for power electronics system, see among many references, for example, SIMPLORER [5], POSTMAC [6], SIMSEN [7], ANSIM [8], and PSCAD [9], have been proposed in the recent years. Such software packages give a more or less user-friendly environment, however not using the concept of visual design. A lot of attention has recently been give to libraries of models for the various components of a power electronic system developed, in the Matlab ${ }^{(1)}$ and Simulink ${ }^{(}$environment. In [10] an interactive power electronic system simulation package SIMUSEC "Simulation des Systemes Electrotechniques en Commutation" is presented. Paper [11] gives an overview on the subject of modelling and simulation of power electronic converters and makes reference to a library of models for the Simulink environment called SIMUPELS also for the power electronics converter and electrical machines. Another reference, is the MatEMTP [12]: a transient analysis program in Matlab ${ }^{(B)}$ M-files, that can perform EMTP type simulations entirely in Matlab ${ }^{*}$.

VCSP also allows a quite flexible and open simulation activity using its own independently developed library of block function. However, bearing in mind that simulation activities sooner or later require code production for realtime control applications, in particular rapid prototyping of the target systems, VCSP was designed to bridge this gap. Therefore, in VCSP a graphical environment of Simulink is used to build a true development system for motion control system algorithms and their blocks, employing its own blocks library and supported by simulation and estimation tools. The results are prepared for immediate code generation using the Real-Time Workshop of Simulink ${ }^{\circ}$. Some references where the concept of visual design is used to develop simulation tools are $[13,14,15]$. In [13], a visual software product developed specifically for Microsoft Windows operating systems, called Hypersignal Block Diagram is presented. This software package provides a graphical design environment that allows complex digital signal processes to be visually programmed. A similar approach is used in [14] which is developed for use with Matlab ${ }^{2}$ and Simulink ${ }^{\text {(B) }}$ but only for basic signal processing tasks. Paper [15] gives an overview of simulation as well as real-time acquisition, programmed in LabVIEW. Advantages and limitations of LabVIEW for such applications are discussed in the paper.

The software package Matlab ${ }^{\circledR}$ and Simulink ${ }^{\circledR}$ plays a crucial role for solving many problems in control and digital signal processing and is a de-facto standard in the signal processing community, so no further justification is required.

The simulation environment of Matlab ${ }^{(\text {) }}$ and Simulink has a high flexibility and expandability which allowed the possibility of development of a set of functions for a detailed analysis of the electrical drive. In other way, Simulink ${ }^{(3)}$ offers a graphical user interface that allows selection of functional blocks, their placement on a worksheet, selection of their functional parameters interactively, and description of signal flow by connecting their data lines using a mouse device. Another advantage for the use of Simulink ${ }^{(8)}$ is an automatic $C$ source code generation with the Real-Time Workshop ${ }^{\text {TM }}$

Most of the advanced motion control methods nowadays are based on the space phasor method approach [16], [17]. The purpose of the present contribution is to present the digital vector control signal processing (VCSP) blockset 
for use with Matlab and Simulink ${ }^{8}$. The organization of the present work is based on the experience acquired in previous activities connected to modelling of $\mathrm{AC}$ drives operation either using hardware [18,19] or software approaches [20]. The originality of this blockset consists in extending Simulink $^{(3)}$ for use in the design, simulation, and rapid prototyping of digital signal processing algorithms in motion control systems. The VCSP blockset together with Real-Time Workshop facilitates the rapid design, simplifies the prototyping of several vector control methods and can also be used as a tool for teaching and demonstration. In fact, signal processing for vector control systems theory is typically taught using a block diagram approach because it conveys the information efficiently and allows students to learn quickly. In section 2 we give a brief description of the motivation for visual design, different structure of the simulation tools, decomposition in subsystems for simulation and structure for control. In section 3 we give an overview about blockset functions. Next, we present several examples using the VCSP blockset. Finally, in section 5 conclusions and some ideas for further research are given.

\section{PRELIMINARIES}

The basic computer technique used today for evaluation of engineering solutions is simulation. Recently several approaches to the simulation problem have been presented $[21,22,23,24,25,26]$, considering the simulation in view of the control design. In the first place motivation for visual design is presented, next we will describe the basic different classes of simulations involved in electrical drives. As a systematic approach of different drives, a decomposition in subsystems is finally introduced.

\section{A. Motivation for Visual Design}

Visual design is a more natural design methodology than textual design. Visual design follows the principles of modulat design, object-oriented design, reusable blocks, support for hierarchy project and self-documentation because it inherently illustrates the algorithm being performed. This simulation environment provides interactive control and observability of the design at execution time. It is possible to change parameters and immediately observe the results with waveform displays. This methodology is implemented by the graphical user

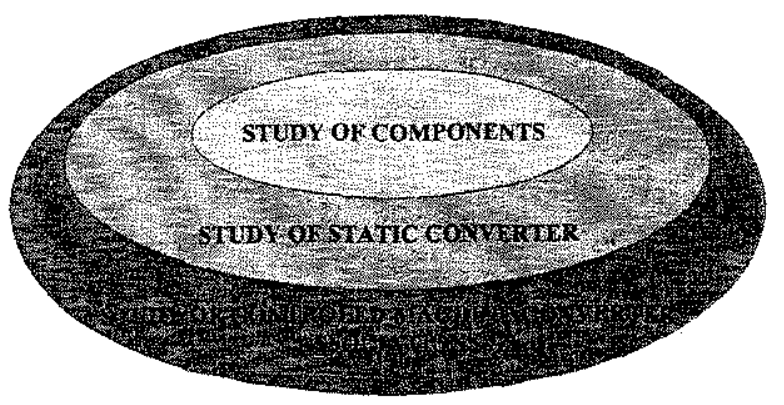

Fig. 1. The general layer structure of simulations interface of the Simulink that allows users to select the necessary blocks.

\section{B. Different Simulation Levels}

Simulation can be oriented towards a special part of a system depending on the objective, see fig. 1. In the first layer the power components are simulated and for this it is necessary to provide a precise description about of the structure of semiconductor. Various models describing semiconductor components exist. Depending on the purpose of the simulation the complexity of the model is selected. The middle layer is the next appear level of the simulation and is more complex. It is useful for study and test of topologies of static converters.

In order to simulate a static converter the time step in the simulation has to be small enough to sample the dynamics of the electronic circuit. For motion control however, an ideal model for static converter (functional description) is satisfactory, since only the overall dynamic behaviour has to be simulated. In fact, details about components behaviour are less important when designing the controller. However, the time-delays caused by the modulation and other non-linear effects (for example, dead time) in the static converter influence the overall behaviour of the controller and must not be disregarded. The model of the static converter should at least include ideal representation of semiconductor switches.

As the main objective of this paper is the simulation of controlled machine-converter associations, this has to be done as modularly as possible to help the user to analyse and understand the problems. A simple representation of the rest of the system (components, static converter) is appropriate

\section{Decomposition in Subsystems}

The electrical drive system is constituted by three subsystems: the power supply, the electrical motor and the mechanical load as described in figure 2 . The power supply can be separated in three blocks: static converter, control of power switches and control methodology. The first and second blocks are very dependent on the topology of static converters The control block is the most important for conception and design of algorithms.

Independently of the electrical motor used, it is possible to make a decomposition in two parts: an electromagnetic part and a mechanical part. The first part comprises the mathematical model of the motor. This block depends on the electrical motor type. On the other hand, the

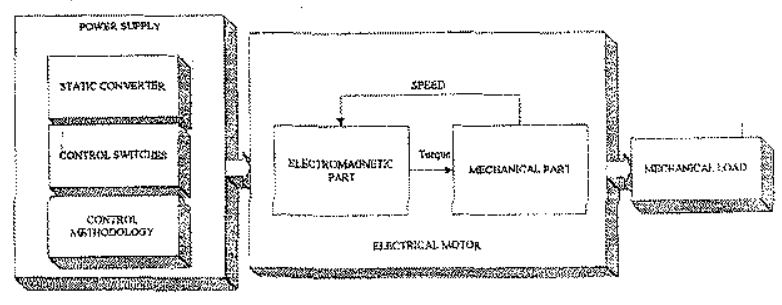

Fig. 2. Decomposition of an electrical drive in subsystems 
mechanical part comprises the inertia and other mechanical aspects. The connection between the blocks is the rotating speed that acts as a feedback on the electromagnetic part. Similarly, the electromagnetic part acts as a feedback on the power supply inducing, for example a voltage drop. Finally, the driven load acts as a feedback on the mechanical part of the electrical motor primarily through the load torque and inertia.

All the subsystems of an electrical drive are, as illustrated in the previous paragraph, interconnected and their function are interdependent. This way, as each subsystem has specific characteristics, it results in a wide range of time constants and hence differential equations systems with high dynamic range of variables to solve using a simulator. A practical approach requires models with very different levels of detail. The design of the decomposition of different levels is a non-trivial aspect. Conceptually, we can view a simulation environment at different abstraction levels. The approach is the formulation of a simulation task at different description levels.

- Functional description : the block is characterised by a "black box" with functionality to explain logical relations among the signals but says nothing about its implementation, for example, inverters, rectifiers, DC-DC converters.

- Description for implementation: this type blocks is characterised by a high degree of transparency for the code generator that produces $\mathrm{C}$ code directly from the block diagram.

The above description levels correspond to different types of blocks. In other words, when modelling is important to decide the level of precision needed, before starting constructing the models. The price to pay for a very accurate model is very often a lower simulation speed. Another way, for efficient code generation is very important the using the discrete blocks.

\section{Control Design}

The decomposition of the controlled system allows to define a certain systematic approach about control system design. The basic principle is illustrated in fig 3 . It is due to Bülher [27]. The controller REM controls the electromagnetic part according to its set-point value, which is provided by a superposed mechanical system controller $\mathrm{R}_{\mathrm{MEC}}$. This controller controls either the rotating speed or the angular position or an other variable of the system.

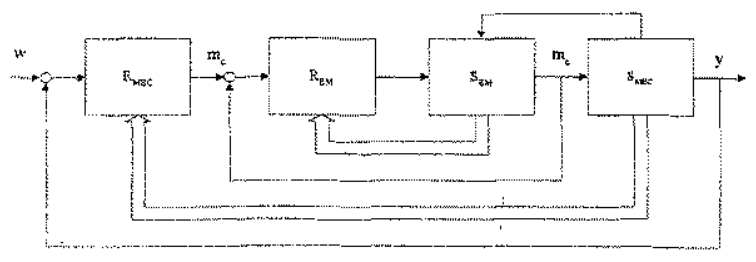

Fig. 3. Diagram of the control structure

\section{BLOCKSET FUNCTIONS}

These blocks provide the signal processing core for vector control systems operation including phase conversion and coordinate transformation, flux vector estimation, torque and torque angle estimation, speed estimation and controllers.

\section{A. Phase Conversion and Coordinate Transformation}

These blocks provide support for all phase conversion and coordinate transformation necessary in several methods for vector control system.

\section{B. Flux Vector and Mechanical Signal Estimation}

These blocks provide core signal estimation processing for flux vector estimation. Such blocks generate the stator or rotor flux estimation based on several flux models. The models are excited by measurable quantities such as voltage, currents, angular speed or shaft position angle. The mechanical signal estimation blocks are able to estimate the speed, torque and torque angle.

\section{Controllers}

These blocks provide many of the basic controller functions used in vector control including PI, PID, PD2, state controllers. Beside the adjustment of the various gains or the sampling period, the numerical resolution and calculation accuracy can be simulated. The scalar and field-oriented control techniques of the induction motor are also implemented.

\section{Functional Blocks and Organization}

In order to simulate some parts of the electrical drives but not using code generation, we have implemented this type of block. We can recognise five groups of there blocks:

- the electrical motors (DC, AC induction or synchronous),

- the several electrical and mechanical loads,

- the static converters (Phase Controlled converters, DC-

$\mathrm{DC}$ converters and DC-AC and AC-AC converters);

- PWM methods (Sinusoidal PWM, Space vectorial modulation, Switching Table, Hysteresis band method) - the system of measured quantities (Analog to digital converter, Digital to analog converter, position and speed measured).

This last feature is particularly interesting for evaluating the required precision and studying the harmful effects of the quantization in the control algorithm

\section{APPLICATION EXAMPLES}

The following sections will show some examples with the VCSP blockset. As shown in fig. 4 the example consists of a DC-to-DC converter (four quadrant) supplying a DC Motor. During the simulation the motor current signal is supplied to the converter. In the 


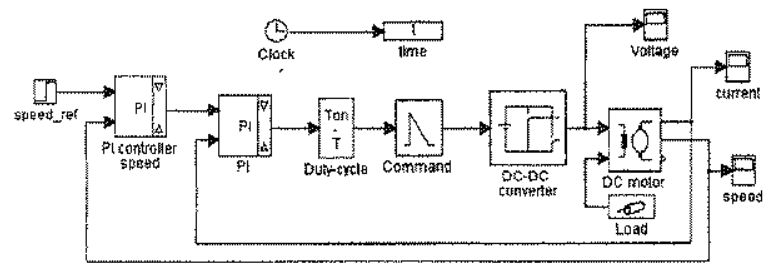

Fig. 4. Simulation model of a DC-DC converter for a DC motor

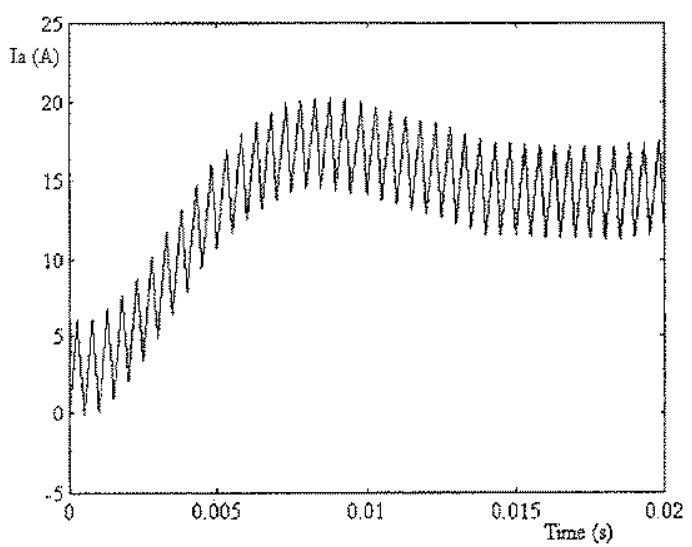

Fig. 5 - Infuence of the current loop

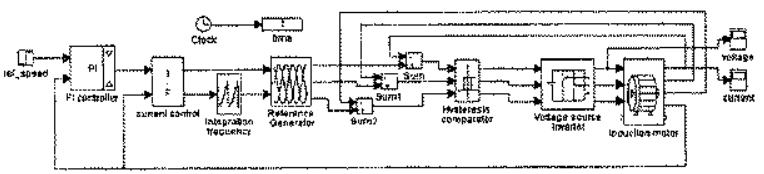

Fig. 6. Simulation model of a induction motor control using indirect flux stabilisation with hysteresis current control

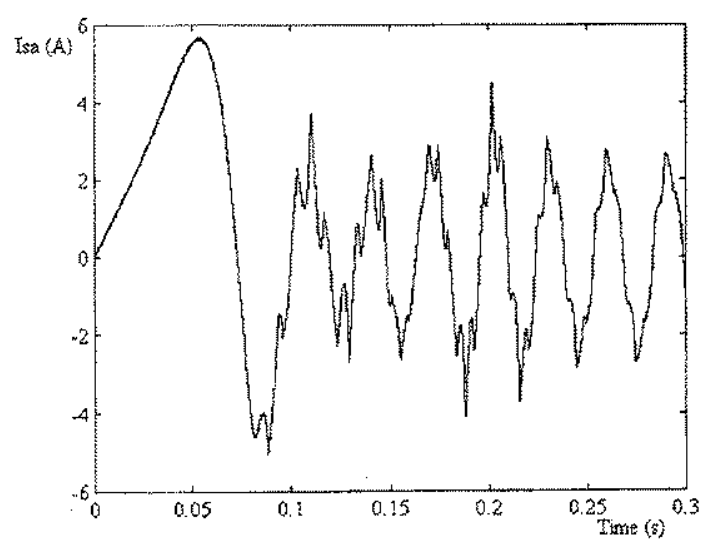

Fig. 7. Induction motor phase current during star-up with hysteresis current controller per phase

simulation result in fig. 5 one can easily see how the startup influences the behaviour of the current controller loop. In fig. 6 an induction motor controlled with indirect flux stabilisation by current control is presented. This example proposes the simulation of control system of the induction motor, where the inverter is controlled by three independent hysteresis loops. Typical signal waveforms for the hysteresis controllers is shown in fig 7. Another example of the induction motor control is illustrated in fig. 8 , where the static converter is controlled by classical PWM. In figures 9-11 the simulation results in speed reversal from $140 \mathrm{rad} / \mathrm{s}$ to $-140 \mathrm{rad} / \mathrm{s}$ are shown. In this system the voltage is manipulated according to the real and imaginary components of the space phasor voltage. In fig. 12 the simulation of the two algorithms for estimation rotor flux is presented. First algorithm applies a current model in rotor coordinates. Figure 13 shows the simulation results for the first algorithm. Figure 14 shows the results for the algorithm of estimation in field coordinates.

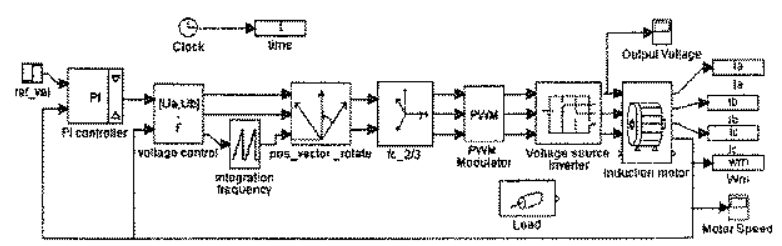

Fig. 8. Simulation model of a induction motor control using indirect flux stabilisation by voltage control

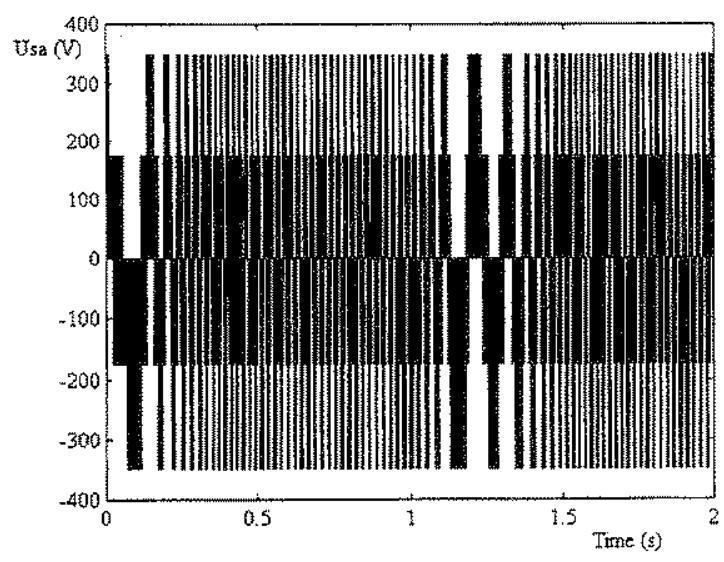

Fig. 9. Phase voltage of the induction machine during speed teversal in the system of fig. 8

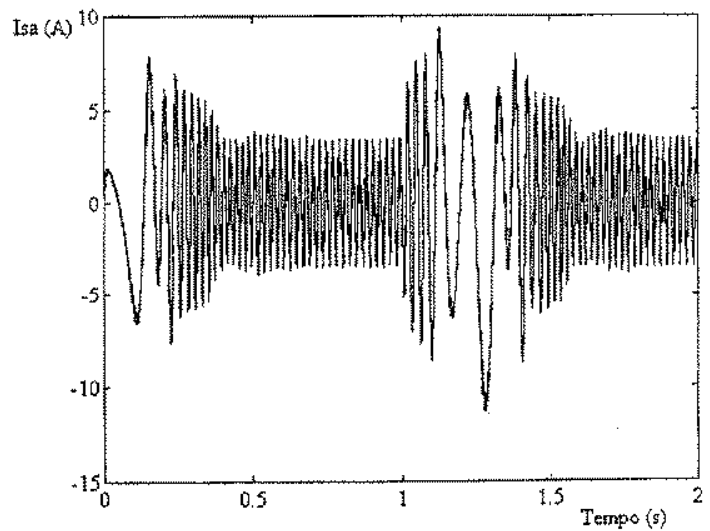

Fig. 10. Phase current of the induction machine during speed reversal in the system of fig. 8 


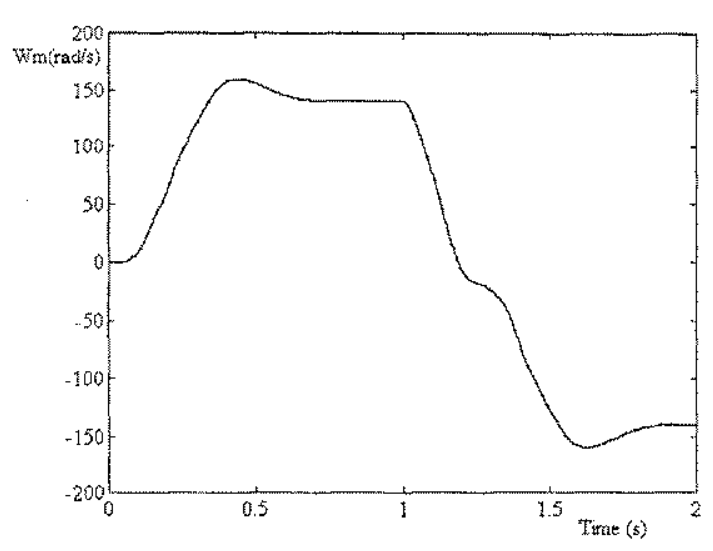

Fig. 11. Speed reversal in the system of fig. 8

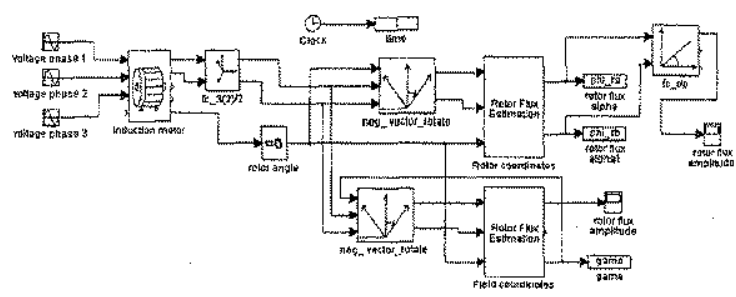

Fig. 12. Simulation models for estimation rotor flux

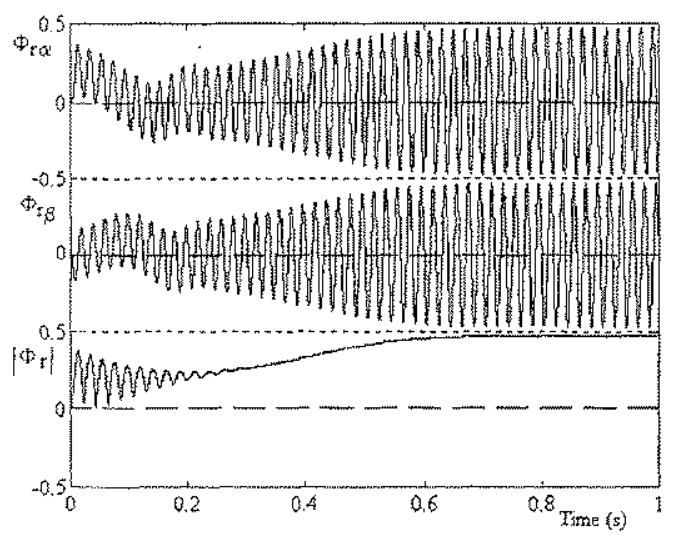

Fig. 13. Rotor flux estimation in rotor cootdinates

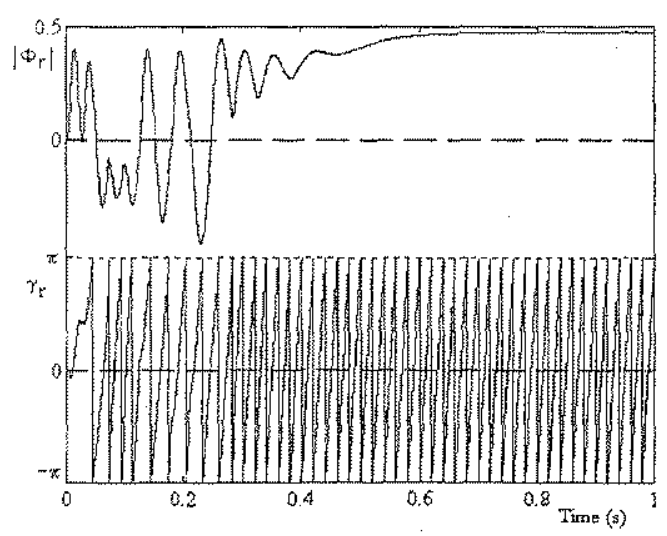

Fig. 14. Transient behaviour for rotor flux estimation with algorithm in field coordinates

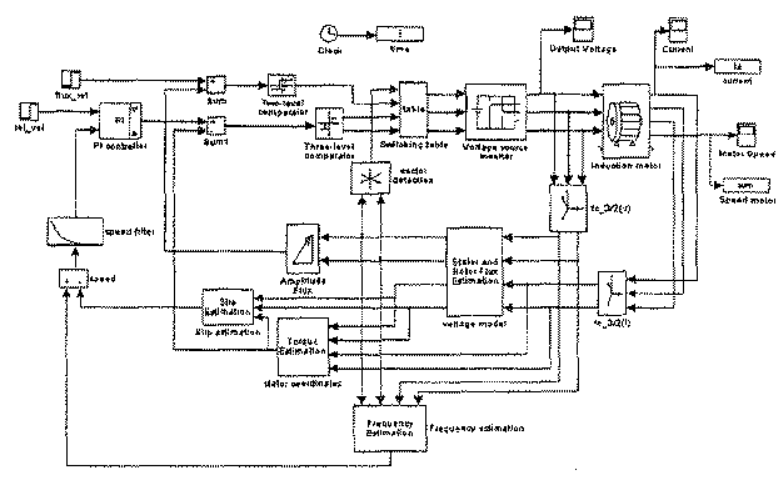

Fig. 15. Direct flux and torque control of inverter-fed induction motor

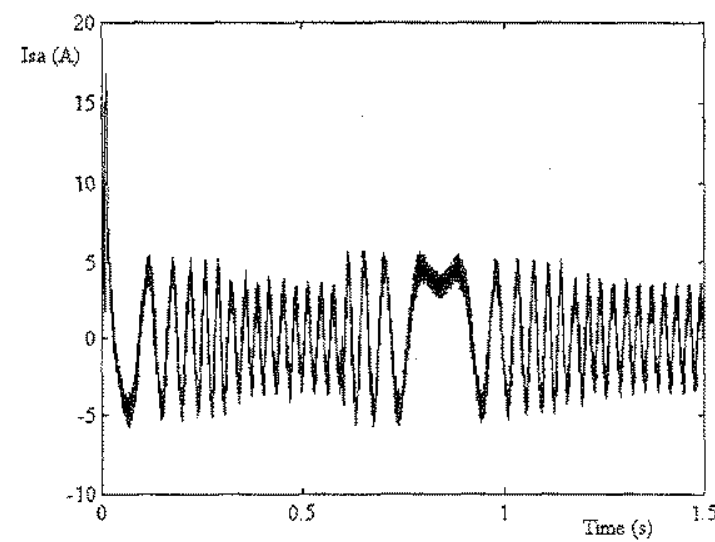

Fig. 16. Phase current of the induction machine during speed reversal in the system of fig. 15

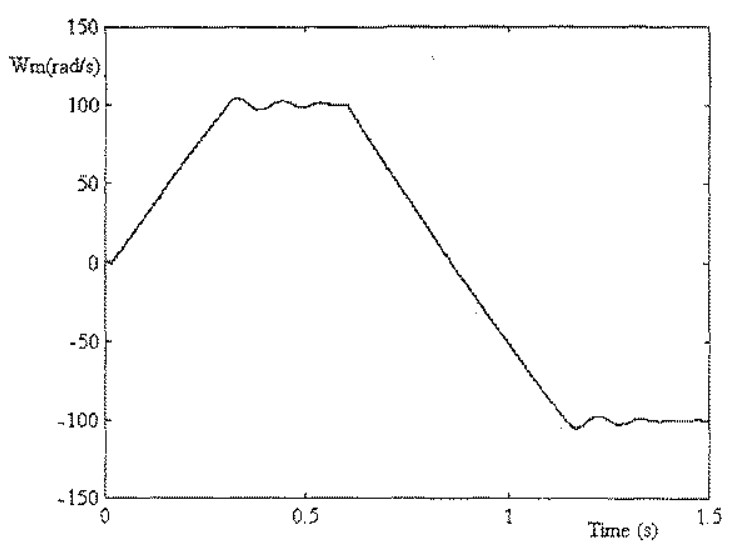

Fig. 17. Speed teversal in the system of fig. 15

Finally, in fig. 15 the simulation of direct torque control without motor speed direct measurement, where the torque and stator flux are regulated to their command values by selecting the switching state which gives the proper changes in the torque and flux. In figures 16 and 17 the simulation results in speed reversal from $100 \mathrm{rad} / \mathrm{s}$ to -100 $\mathrm{rad} / \mathrm{s}$ are shown.

\section{CONCLUSIONS AND FUTURE WORK}

Motion control is by nature a pluridisciplinary field, involving disciplines such as signal processing, identification and control theory, process programming, 
power electronics and electrical machines. The rapid progress realised in the field of Digital Signal Processors (DSP), characterised by their greater computing and processing power allows to implement complex and flexible algorithms for motion control. These features combined with use, for their programming, of visual design tools create, as illustrated by this work, new possibilities for the system conception and will have a sensitive impact on system design time and costs. Another useful characteristics this work, is using a block diagram approach to teaching. The short learning curve that results from the visual design is considered one key reason why this approach is considered successful.

The simulator envitonment is still an ongoing process, some further ideas related with this work are the following: realisation of additional blocks, integration with hardware using the Real-Time Workshop package of Matlab (DS1102 Dspace).

\section{REFERENCES}

11] P. Antognetti, G. Massobrio, Semiconductor Devices Modeling with SPICE, Mc. Graw-Hill, New-York, 1988

[2] Mixed Signal Design Simulation Guide, Analogy, Inc, 1994

[3] EMTP Rule book, Bonneville Power Administration, Portland, Oregon

[4] EUROSTAG, Software for the Simulation of Power Systems Dynamics, Electricité France, Tractebel, 1990

[5] SIMPLORER Version 3.2 for Windows - Quicksart, SIMEC - Simulation and Automation, Germany, 1994

[6] Notice D'Utilisation du Logiciel POSTMAC, LEEI, ENSEEIHT, Toulouse, 1994

[7] A. Sapin, J. J. Simond, "SIMSEN: A Modular Software Package for the Analysis of Power Networks and Variable Speed Drives", in Proc. of the EPE Symp. on Electric Drive Design and Applications, Lausanne, 1994

18] G. Rafajlovski, D. Manov, "Digital Simulation of Field Oriented Control Using ANSM Program", in Proc. of the $8^{\text {th }}$ Mediterranean Elect. Conf. on Industrial Applications in Power Systems, Computer Science and Tele., May, 13-16, 1996, Bary, Italy

[9] A.M. Gole, O.B. Nayak, T. S. Sidhu, and M.S. Sachdev, "A Graphical Electromagnetic Simulation Laboratory for Power Systems Engineering Programs", IEEE Transactions on Power Systems, vol. 11, no. 2, May, 1996

[10] A.Ba-razzouk, A. Pittet, A. Chériti, V. Rajagopalan, "Simulink Based Simulation of Power Electronic Systems", in Proc. of the IEEE $4^{\text {th }}$ Workshop on Computers in Power Electronics, 94TH0705 4, 1994

[11] V. Rajagopalan, "Modeling and Simulation of Power Electronic converters for Power Supplies", in Proc. of the Industrial Electronics Conference, 1995

[12] J. Mahseredjian, Fernando Alvarado, "Creating an Electromagnetic Transients Program in Matlab: MatEMTP", IEEE Transactions on Power Delivery, vol. 12, no. 1, Jan., 1997
[13] Hypersignal ${ }^{\text {Bis }}$ Block Diagram, Product Document: HSMK9105, Hyperception, Inc., U.S.A.,1996

[14] The DSP Blockset for use Matlab ${ }^{\circledR}$ and Simulink ${ }^{\circledR}$, The Math Works, Inc., U.S.A., 1996

[15] R. Jamal, L. Wenzed, "The applicability of the Visual Programming Language LabView to Large RealWord Applications", in Proc. of the 11 th Int. IEEE Symp. on Visual Languages, September 5-9, Darmstadt, Germany, 1995

[16] W. Leonhard, Control of Electrical Drives, Springer Verlag, 1985

[17] P. Vas, Vector Control of AC Machines, Clarendon Press - Oxford, 1990

[18] S. Colombi, J. Mignan, "Numerical Simulation of the Stator Currents, Flux and Torque Controls of an $A C$ Motor", in Proc. European Power Electron. Conf., Aachen, 1989

[19] R. E. Araújo, J. Gonçalves, A. Tavares, D. S. Freitas,. "Phasor Visualizer for Investigation, Teaching and Control of Induction Motor", in Proc. of the $8^{\text {th }}$ Mediterranean Elect. Conf. on Industrial Applications in Power Systems, Computer Science and Tele., Bary, Italy, 1996

[20] R. E. Araújo, J. Gonçalves, D. S. Freitas," Analogue Signal Processing Instrument for Real-Time Phasor Visualization in Induction Motor Drives", in Proc. of the $2^{\text {nd }}$ Portuguese Conf. Automatic Control, Porto, Portugal, 1996

[21] R. E Araújo, Controlo do Motor de Indução Trifásico Baseado no Princípio da Orientação do Campo, Master Thesis (in Portuguese), FEUP, 1991

[22] X. Roboam, B. Dagues, J. Hapiot, J. Faucher, "Elaboration of a Simulation Software by the SOSIE Method. Validation of a Flux Observer for Induction Motor", in Proc. of the Power Electron. Spec. Conf, 29 June - 3 July, Toledo, Spain, 1992

[23] B. Dagues, F. Chouzal, X. Roboam, "POSTMAC: A powerful system for digital simulation of converterinduction machine assemblies", in Proc. of the IMACS'93, 7-9 July, Montreal, Canada, 1993

[24] L. Gerbaud, F. Pazos Flores, A. Bolopion, Y. Baudon, J.P. Ferrieux, "On the Use MACSYMA Symbolic Language to Generate Simulation Software for the Control of Converter-Machine Drives", in Proc. European Power Electron. Conf, Brighton, 1993

[25] U. Knorr, "IDAS - A Sophisticaded Simulation Tool for Power Electronics and Drive Systems", in Proc. of the EPE Symp. on Electric Drive Design and Applications, Lausanne, 1994, Lausanne, 1994

[26] L. Antognini, M. Khoury, C. Dayer, L. Kreindler "New Software Tools for Design and Implementation of Complete High Performance Motion Systems", in Proc. of the EPE Symposium on Electric Drive Design and Applications, Lausanne, 1994, Lausanne, 1994

[27] H. Bülher, "Impact of Modern Automatic Control Theory on Electrical Drives", in Proc. of the IFAC $10^{\text {th }}$ World Congress on Automatic Control, Munich, 1987 